NBSIR 79-1604

\title{
A COMPARISON OF CENTRFFuge AND FrEEZING CALORIMETER METHODS FOR MEASURING FREE WATER IN SNOW
}

R. N. Jones

Electromagnetic Fields Division National Engineering Laboratory National Bureau of Standards

Boulder, Colorado 80303

May 1979 

$+$

NBSIR 79-1604

\section{A COMPARISON OF CENTRFFGE AND FREEZING CALORIMETER METHODS FOR MEASURNGG FREE WATER IN SHOW}

R. N. Jones

Electromagnetic Fields Division

National Engineering Laboratory

National Bureau of Standards

Boulder, Colorado 80303

May 1979

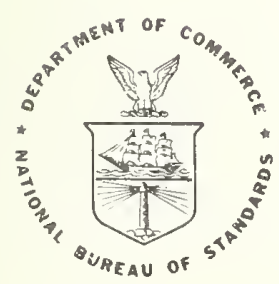

U.S. DEPARTMENT OF COMMERCE, Juanita M. Kreps, Secretary

Sidney Harman, Under Secretary

Jordan J. Baruch, Assistant Secretary for Science and Technology

ISATIONAL BUREAU OF STANDARDS, Ernest Ambler, Director 



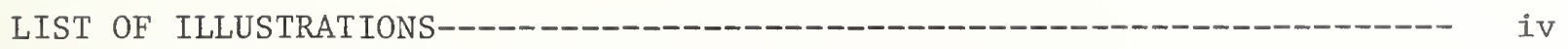

ABSTRACT----- ---

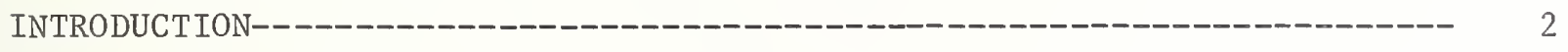

BACKGROUND-- - -

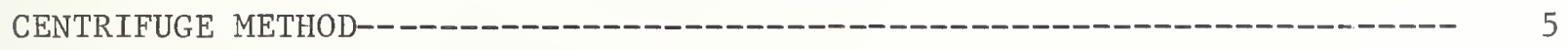

FREEZING CALORIMETER METHOD--:-------------------------------------- 8

THE TWO METHODS COMPARED-------------------------------------------- 12

CENTRIFUGE EXPERIMENTS WITH SAND----------------------------------- 28

CONCLUS IONS---------

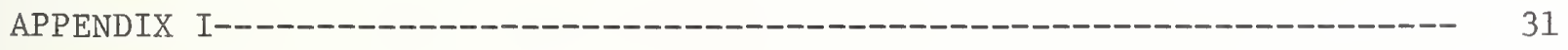

APPENDIX II-- -

ACKNOWLEDGMENT------- 38

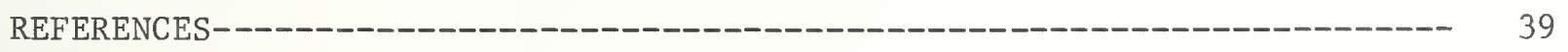


The hand-driven centrifuge system-- 3

Snow sampling tubes and retainer screen--------------------- 4

The freezing calorimeter system

4 A comparison of percent free water in snow

as determined simultaneously by freezing calorimeter and $35 \mathrm{~m} 1$ centrifuge

Percent free water in snow, Hideaway Park, CO 2/23/78 18

Percent free water in snow, Hideaway Park, CO

$2 / 28 / 78$

Percent free water in snow, Hideaway Park, CO

$3 / 01 / 78------\quad 20$

Percent free water in snow, Hideaway Park, CO

$3 / 02 / 78------21$

Percent free water in snow, Hideaway Park, CO

$3 / 07 / 78-----22$

Percent free water in snow, Hideaway Park, CO

$3 / 09 / 78-------\quad 23$

Percent free water in snow, Hideaway Park, CO

$3 / 21 / 78-------\quad 24$

Percent free water in snow, Hideaway Park, CO

$3 / 22 / 78-\cdots----25$

Percent free water in snow, Hideaway Park, CO

$3 / 23 / 78-------26$ 
A Comparison of Centrifuge and Freezing Calorimeter Methods for Measuring Free Water in Snow

\author{
R. N. Jones \\ National Bureau of Standards \\ Boulder, Colorado 80303
}

\begin{abstract}
In using microwave measurements in hydrological studies of snowpack or avalanche prediction, the presence of free water in the snow has a strong influence on observed data because it affects the dielectric characteristics. Although several methods are in use for determining the percent of free water in snow, there is very little information in the literature as to how well the various methods agree. This paper reports on a comparison of two popular methods; namely, the centrifuge and the freezing calorimeter. Results from measurements over a two-month period in the Colorado mountains in the winter of 1978 indicate serious disagreement between these two methods. Some reasons for the disagreement are presented and verified. This raises some important questions pertaining not only to what the two methods actually measure, but also which methods may be appropriate for particular applications.
\end{abstract}

Key Words: Centrifuge; comparison of measurement methods; free water; freezing calorimeter; hydrology forecasting; microwave remote sensing; snow. 
During February and March 1978, measurements of the presence of free water in snow were made at three sites in the Colorado mountains. Most of the measurements were of snow samples collected at the surface, and two different measurement methods were used: the freezing calorimeter and the $35 \mathrm{ml}$ hand-driven centrifuge. Data from these two methods resulted in wide disagreement in many instances. Presented here are descriptions of the two systems, techniques employed, resulting data, and some specially devised experiments to verify the differences which appear to exist. In general, the percent of free water levels determined by the freezing calorimeter method are significantly higher than those determined with the hand-driven centrifuge method. Reasons for the disagreement between the two methods are given together with supporting experimental evidence.

\section{BACKGROUND}

Electromagnetic techniques for gathering hydrological data are being investigated extensively by the National Aeronautics and Space Administration (NASA) for possible use in large area and world-wide hydrological studies using both active and passive microwave equipment.* The presence of free water in snow is one parameter believed to have a

\footnotetext{
* Passive systems utilize natural microwave radiation from the earth, whereas active systems transmit a signal and measure the change in intensity and/or phase of the return (reflected) signal.
} 

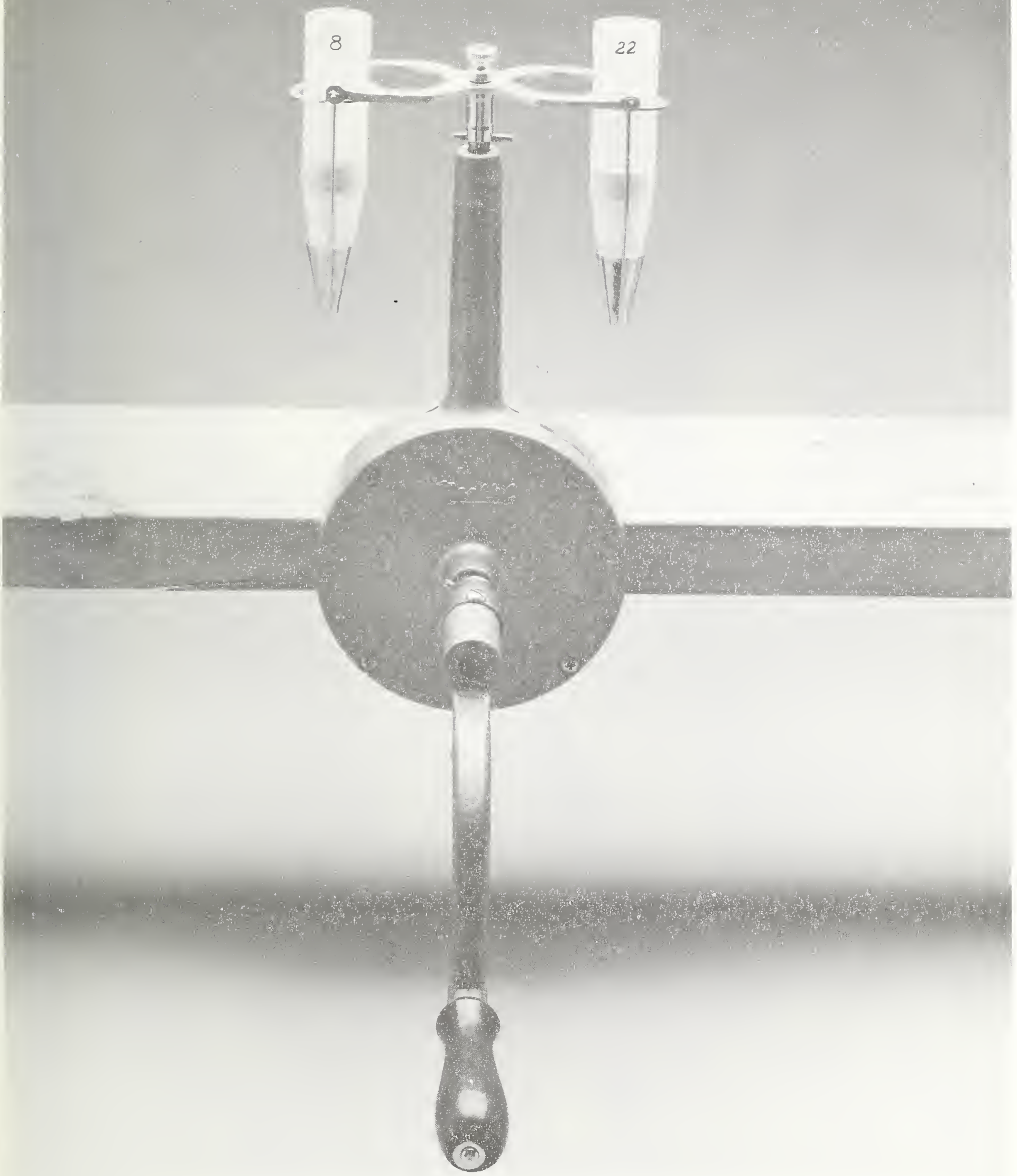

Figure 1. The hand-driven centrifuge system. 


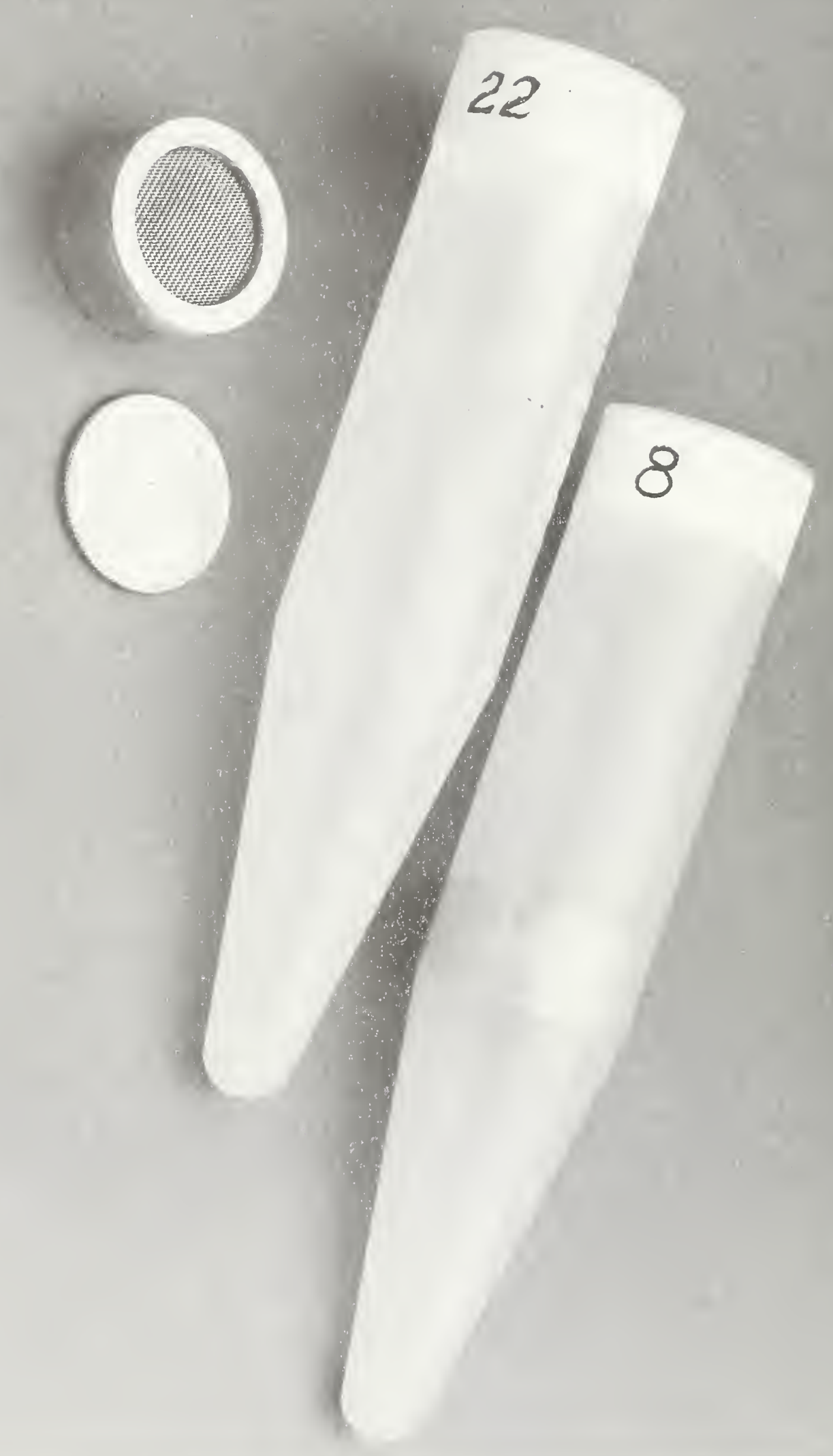

Figure 2. Snow sampling tubes and retainer screen. 
significant effect upon data obtained by these microwave systems [1,2] . The work described here was done in conjunction with a series of radiometer experiments carried out by the National Bureau of Standards (NBS) Electromagnetic Fields Division under contract from NASA. Although the work described utilized only two methods for determining snow quality (or free water content), several other methods are available. These are described briefly in a paper by Langham [3]. Bergman [4] worked extensively with the freezing calorimeter method to determine its precision and limitations relative to snow types and temperature; however, a literature search failed to locate any previous efforts to compare the results obtained by different methods.

\section{CENTRIFUGE METHOD}

The centrifuge method has been described by LaChapelle [5] and later with improvements by Langham [6], who refined the method to reduce errors from air friction melting. Extensive use of the method was also reported by Carrol1 [7]. Figures 1 and 2 show the equipment used in obtaining the data in this report. The hand-driven centrifuge shown in figure 1 holds two polyeurethane test tubes having a snow-sample capacity of approximately $35 \mathrm{ml}$ in the upper section. Figure 2 shows the test tubes used, together with the wire mesh gratings used to retain snow in the upper section of the tube during centrifuging. The free water is collected in the lower section and its volume read on the graduated scale. Snow retainer screens had openings of approximately $0.16 \times 0.16 \mathrm{~mm}$ (100 mesh), this being large enough to allow the water to pass through but small enough to prevent the smallest snow particles from reaching 
the lower section. Other mesh sizes up to approximately $0.7 \times 0.7 \mathrm{~mm}$ were tried without noticeable difference or apparent particle migration during the centrifuge procedure. Such a small mesh size did have one slight disadvantage which was an inconvenience: after the snow above the screen had melted, the tubes required additional centrifuging to overcome surface tension and to force the water into the lower portion where the final total water volume could be determined. To obtain the centrifuged liquid water volumes, two precautions were observed in an effort to minimize error. The first was to use the repeated centrifuge procedure described by Langham [6] and Carrol1 [7] to eliminate error due to air friction melt. The second precaution was to bring the test tubes to ambient snow temperature by embedding them in the wall of the snow pit well before use.

The most serious shortcoming associated with this method was the inability to determine small centrifuged water volumes accurately. The minimum graduation on the test tube was $0.5 \mathrm{ml}$ so that water volumes could be approximated to only $\pm 0.1 \mathrm{~m} 1$. Assuming a typical final melted volume of $15 \mathrm{ml}$, this places a \pm 0.7 percent uncertainty upon the measurement. For final melted volumes smaller than $15 \mathrm{~m} 1$, the percentage uncertainty due to this error source, of course, becomes greater.

The centrifuge has a gear ratio of approximately fifteen to one, and five turns of the handle over a period of 3 to 5 seconds were used. This procedure subjects the snow samples in the test tubes to a force of more than two hundred and fifty times the force of gravity for a period 
of 2 to 4 seconds. This procedure was adopted after some experimentation which showed that sustaining the centrifuging for longer periods did not cause additional water to collect in the tubes. Also, longer periods of centrifuging can cause melting due to air friction with resulting errors in determining the true amount of free water.

During the period of these experiments, concern arose that the centrifuge process did not remove all of the free water from the sample, especially since the centrifuge values were generally lower than those of the calorimeter. As one means of testing this possibility, an experiment was conducted wherein centrifuged snow samples were quickly recentrifuged, but in an inverted position. Several repetitions of the procedure did not produce additional free water.

At this point, some additional discussion is appropriate pertaining to the snow sample collection techniques used with the centrifuge method. Early in the experiment period, the practice for surface snow sampling was to move the two tubes (fig. 2) through the snow surface in the same direction and side by side. While this did allow the two samples to be as nearly identical as possible, it was difficult to collect a large enough sample, especially when attempting to detect small amounts of free water. Later, we began to use a slightly different method which facilitated packing more snow into the tubes. This technique involved taking one tube in each hand and moving them in opposite directions and toward one another. When the tubes came close together, this opposing 
motion forced additional snow into the tubes producing a larger sample. As a result, however, it appears from the data that there was larger disagreement between the results of the two samples. Notice that the centrifuge pairs appear to be in closer agreement for the early (February) weeks of observation than for the later (March) weeks when the second method came into use (see figs. 5-14). It is believed that the second method verifies the fact that there is considerable local variation in the amount of free water and that such variation occurs within distances of the order of $50 \mathrm{~cm}$.

FREEZING CALORIMETER METHOD

Pictured in figure 3 is the apparatus for the freezing calorimeter method including three beam balance, stainless steel calorimeter (vacuum bottle), digital thermometer and temperature probe, stop watch, and calorimeter fluid. For these experiments, the fluid was a type of silicon, SF-96-5, produced by the General Electric Company, * which has a specific heat of approximately $0.44 \mathrm{cal} / \mathrm{gram}$ in the region of $-10^{\circ} \mathrm{C}$. This method was first described by Radok [8] and has also been mentioned in some detail by Leaf [9]. The calorimeter heat balance equation describing the heat exchange between the silicon fluid and the snow sample is given by

$$
W_{i} C_{i}\left(t_{2}-t_{1}\right)-S C_{s}\left(t_{2}-t_{s}\right)=L F
$$

*Mention of a specific commercial material is for the purpose of specifying the ingredients used in an experimental procedure and such identification does not imply endorsement or recommendation by the National Bureau of Standards, nor does it imply that the material is necessarily the best available for the purpose. 

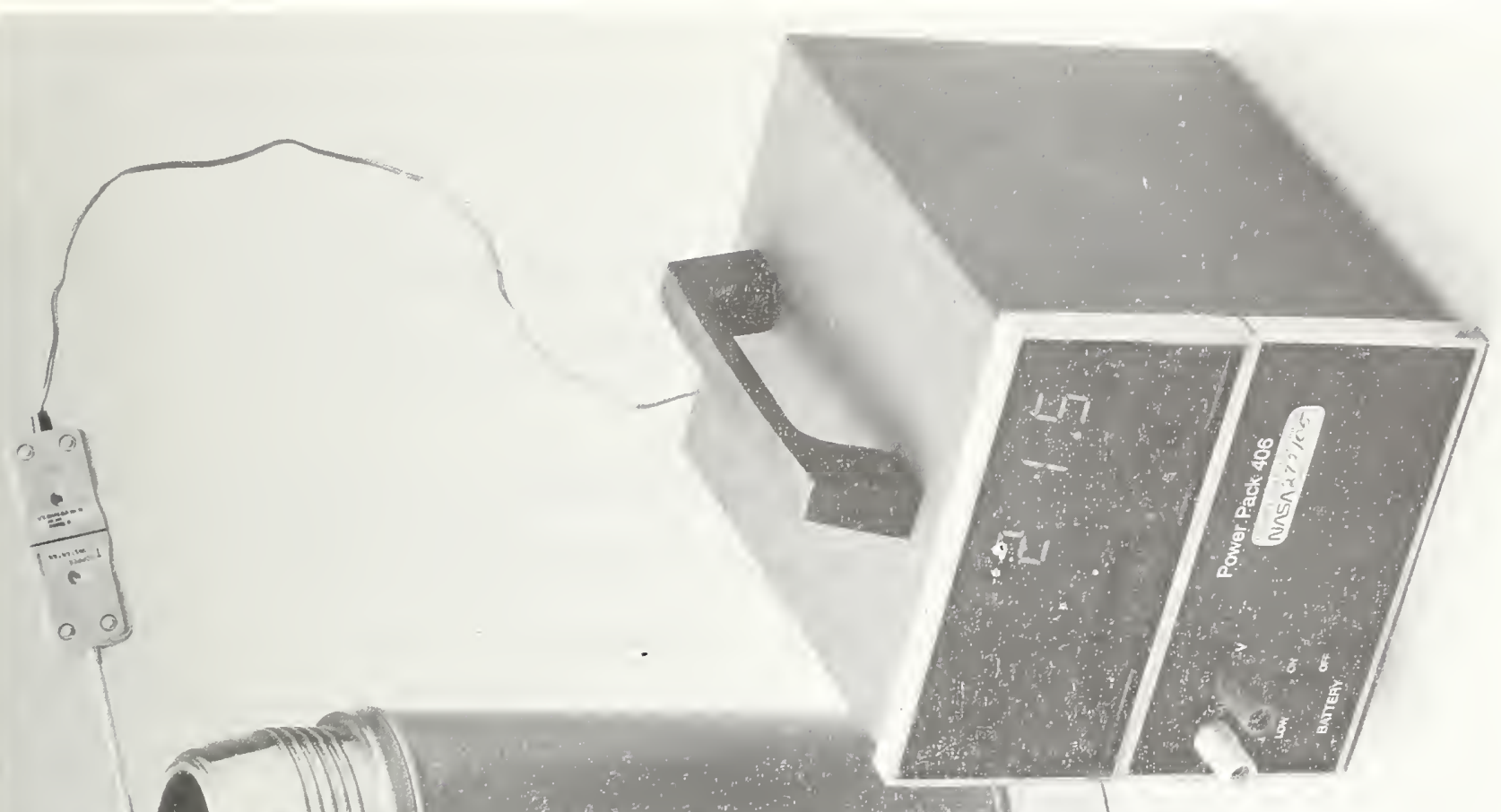
where:

$\mathrm{W}_{\mathrm{i}}=$ weight of silicon fluid in the calorimeter in grams

$C_{i}=$ specific heat of silicon, at mean of temperature before and after adding snow sample, in $\operatorname{cal} /{ }^{\circ} \mathrm{C}$

$\mathrm{t}_{2}=$ temperature of silicon fluid in ${ }^{\circ} \mathrm{C}$ before adding snow sample

$\mathrm{t}_{1}=$ temperature of silicon fluid in ${ }^{\circ} \mathrm{C}$ after adding snow sample

$\mathrm{L}=$ latent heat of fusion of water, $79.71 \mathrm{cal} / \mathrm{gram}$

$\mathrm{F}=$ Weight of free water in the snow sample

S = weight of snow sample added to the calorimeter in grams

$C_{S}=$ specific heat of ice at a temperature midway between $t_{2}$ and $t_{S}$

$t_{S}=$ snow sample temperature $\left(\right.$ in $\left.{ }^{\circ} \mathrm{C}\right)$ before insertion into calorimeter

Here it can be seen that if there were no free water present in the snow ( $F=0)$ all the heat exchange would occur between the silicon and the dry snow crystals. When free water is present the equality is destroyed and a portion of the heat exchange is consumed by the conversion of the free water to ice.

To arrive at a percentage figure for the amount of free water present by weight we define a quality factor:

$$
\begin{aligned}
Q_{f} & =1-\frac{F}{S} \\
\text { or } \quad F & =s\left(1-Q_{f}\right)
\end{aligned}
$$

Upon substituting for $F$ in the above equation, we arrive at the expression: 


$$
Q_{f}=1-\frac{W_{i} C_{i}\left(t_{2}-t_{1}\right)}{L S}+\frac{S C_{s}\left(t_{2}-t_{s}\right)}{L}
$$

and the percentage of free water by weight is than given by:

$$
\% \mathrm{H}_{2} \mathrm{O}=\left(1-\mathrm{Q}_{\mathrm{f}}\right) 100
$$

A sample data sheet, of the type used, and a discussion of the accuracy of the method are given in Appendices I and II. Perhaps the main shortcoming of the freezing calorimeter method is the rather lengthy period (20 minutes) required to measure each sample. This time requirement makes it difficult for a single experimenter to monitor closely the rapidly changing snow surface conditions or to follow the progress of melt water through a snow pack on a warm day.

Because snow conditions apparently change quite rapidly with both time and location, it is not unusual to observe wide variations in results, especially when taken twenty minutes apart. In an attempt to verify the repeatability of the calorimeter results, two operators simultaneously analyzed snow samples taken as closely as possible from the same location on the surface of the snow. The following results were obtained:

Time of Day

Calorimeter 非 "R" Calorimeter 非"S" 
Thus, the repeatability bewteen the two systems " $R$ ' and "S" appears reasonably consistent with the accuracy estimates derived in Appendix II. It is also interesting to note that the centrifuge results, taken at the same time as the simultaneous calorimeter experiments, were considerably lower. (See fig. 6.)

THE TWO METHODS COMPARED

Figure 4 is a summary of the results of centrifuge and calorimeter data accumulated over a period of two months. Each point on the graph is a simultaneous or nearly simultaneous (within 10 minutes) measurement of percent of free water content with the ordinate being the centrifuge results and the abscissa being the calorimeter result. Where a vertical line appears, it means that the two values of that particular centrifuge test did not agree, and they are connected to show that they were derived from the same centrifuge test. In some instances, only one experimenter was available to operate both methods so that centrifuge observations had to be either immediately before or immediately after the calorimeter test. In these cases, there was a lapse of 5 to 10 minutes between collection of the samples. They were, however, collected at the same location. Data from these corresponding but nonsimultaneous experiments appear as a single dot where the two centrifuge samples were in agreement and as two dots connected by a vertical line when they were different. When two experimenters were available, simultaneous sampling from the same location was done, permitting the best comparison of the two methods. These data are identified by triangles surrounding the dots. Triangles surrounding each dot at the end of a vertical line 


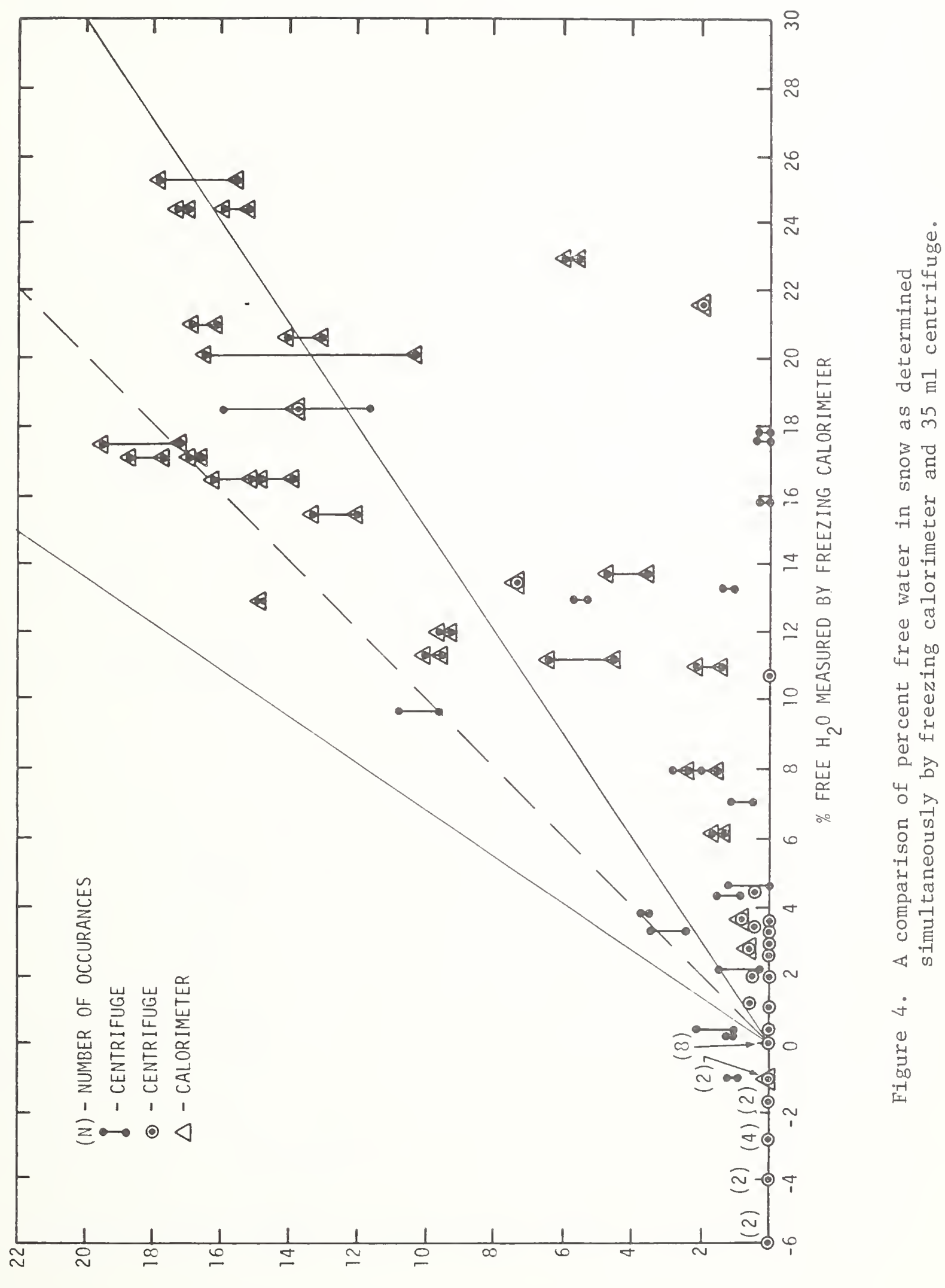

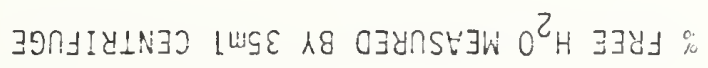


indicate the same calorimeter experiment and the two results from one calorimeter test where there was disagreement between the pair of centrifuge readings.

In some instances, the calorimeter results when computed produced a negative value for percent of free water, and these are shown in figure 4. For best accuracy, the weight of the snow sample should be about 100 grams. This amount of snow when it is dry, light, and cold fills the calorimeter very full so that it is difficult to get good mixing of the snow with the freezing fluid. This produces erratic, nonlinear behavior in the temperature rise within the calorimeter resulting in reduced accuracy in determining the temperature increment $t_{2}-t_{1}$, in equation ( 1 ), with the occasional occurrence of a negative value for free water. In these situations, it is probably safe to assume that the percent of free water present is zero and is considered so in the subsequent data analysis and observations.

If the two methods were in agreement for all the testing done, then each coordinate in figure 4 would have fallen on the diagonal straight line with slope +1 shown in dotted form. It is obvious that the two methods disagree by large amounts in many instances and that the calorimeter usually gives larger values. There are approximately 165 observations including the two results from each centrifuge test and the calorimeter tests. If the negative calorimeter results are interpreted as zero, then only 54 of the 165 comparisons fall with the \pm 33 percent limits of tolerance shown on either side of the dotted line indicating exact agreement . 
Because the freezing calorimeter method can be described mathematically and its uncertainties analyzed with little conjecture, it appears to be in a better state of experimental control than the centrifuge method and is therefore deemed to be more accurate.

For field use, however, the centrifuge method has several advantages over the freezing calorimeter method in that much less paraphernalia is required and less time is required to carry out the test procedure.

Thus, it would be beneficial if the differences in the results obtained by the two methods could be accounted for in a predictable way so as to permit the use of centrifuge methods in the field with the freezing calorimeter method serving as a backup reference standard.

As seen from comparing the data from the two methods, the results from the freezing calorimeter method tend to show a higher free water content than those from the centrifuge method in most instances. One possible reason for this is that the snow does not give up all of the liquid water it contains when subjected to the forces of the centrifuge action. A simple experiment with the centrifuge using sand instead of snow verifies this hypothesis and also indicates that the amount of free water retained is a function of the total surface area of the particles in the sample. 
Previous accuracy estimates of 0.25 percent for the centrifuge method [7] and 1 percent for the calorimeter method [9] have been given in the literature. The error analysis in Appendix II does not disagree radically with the 1 percent for the calorimeter method; and, for the centrifuge method, a 1 percent uncertainty would appear plausible, especially in light of possible local variations in free water.

Assuming the foregoing accuracy estimates to be valid, then it is logical to conclude that the two methods do not measure the same phenomena, or that water may be present in another form in varying amounts that are detectable with the freezing calorimeter but not with the centrifuge. To investigate this possibility, an experiment was conducted whereby the snow sample was centrifuged before being put into the calorimeter. This was done in such a way as to assure that no melt occurred between the time the snow sample was centrifuged and the short period of one or two minutes later when it was put into the calorimeter. The following results were obtained:

Table 1

Free Water Measured

by Centrifuge

Percent
Additional Water

Measured by

Calorimeter

Date

Time

Percent
$3 / 8 / 78$
$14: 25$
1.6
4.5
$3 / 22 / 78$
$14: 31$
$12.4,12.8$
7.5
$3 / 22 / 78$
$15: 26$
$6.7,7.1$
8.9 
It is unfortunate that a second calorimeter system was not available to determine if the total free water might have equaled the sum of these centrifuge and calorimeter results as shown plotted in figure 12.

Figures 5 through 14 show the data summaries for 10 days of observation where measurements of free water were made frequently by both the centrifuge and the calorimeter methods. Also plotted are the air and snow surface temperatures at the sampling location.

At the Hideaway Park site, the snowpack achieved isothermal conditions by March 20 following several days when air temperatures reached $+5^{\circ} \mathrm{C}$ or higher for most of the daylight hours and probably remained above freezing at night. It is interesting to note that in figure 11 for March 21 and all subsequent days of observation, the free water at the surface measured by the centrifuge method seems to follow the air temperature fluctuations. Also, after the isothermal condition was achieved, there appeared to be somewhat better correlation between the results of the two methods with incidents of very large disagreement being less frequent. From examining figures 5 through 14, it also seems apparent that the incidents of greatest departure between the results of the two methods seemed to occur later during the day after approximately 1400. In several cases, this appeared to occur at the end of the day when there had been significant amounts of free water at the surface. In these cases, the centrifuge indicated far less free water present than did the calorimeter. Situations of this type account for some of the very large disagreements between the two methods shown plotted in figure 4. 
J。 $\exists y \cap \perp \forall y \exists d W \exists \perp$

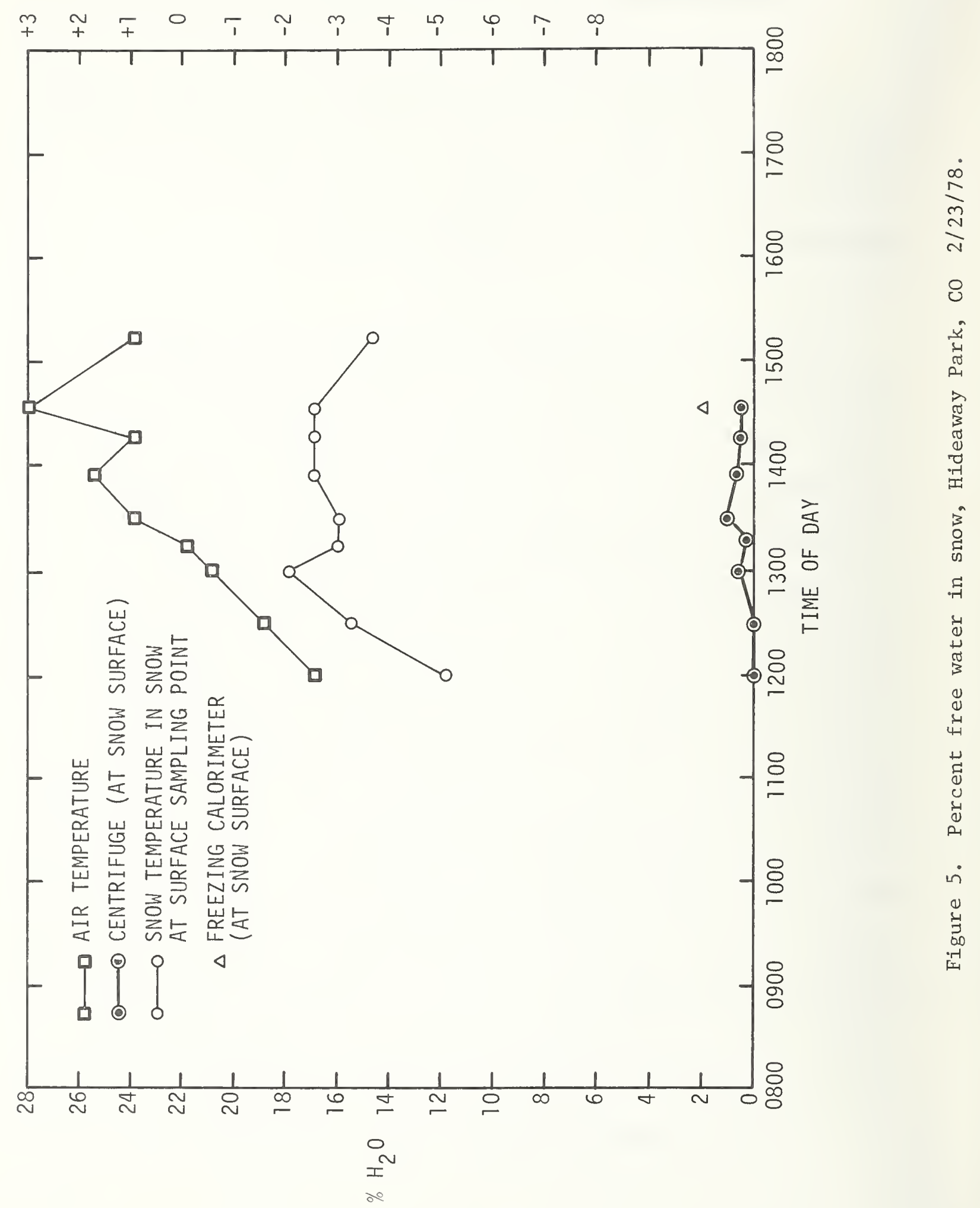


J。 $\exists y \cap \perp \forall y \exists d W \exists \perp$

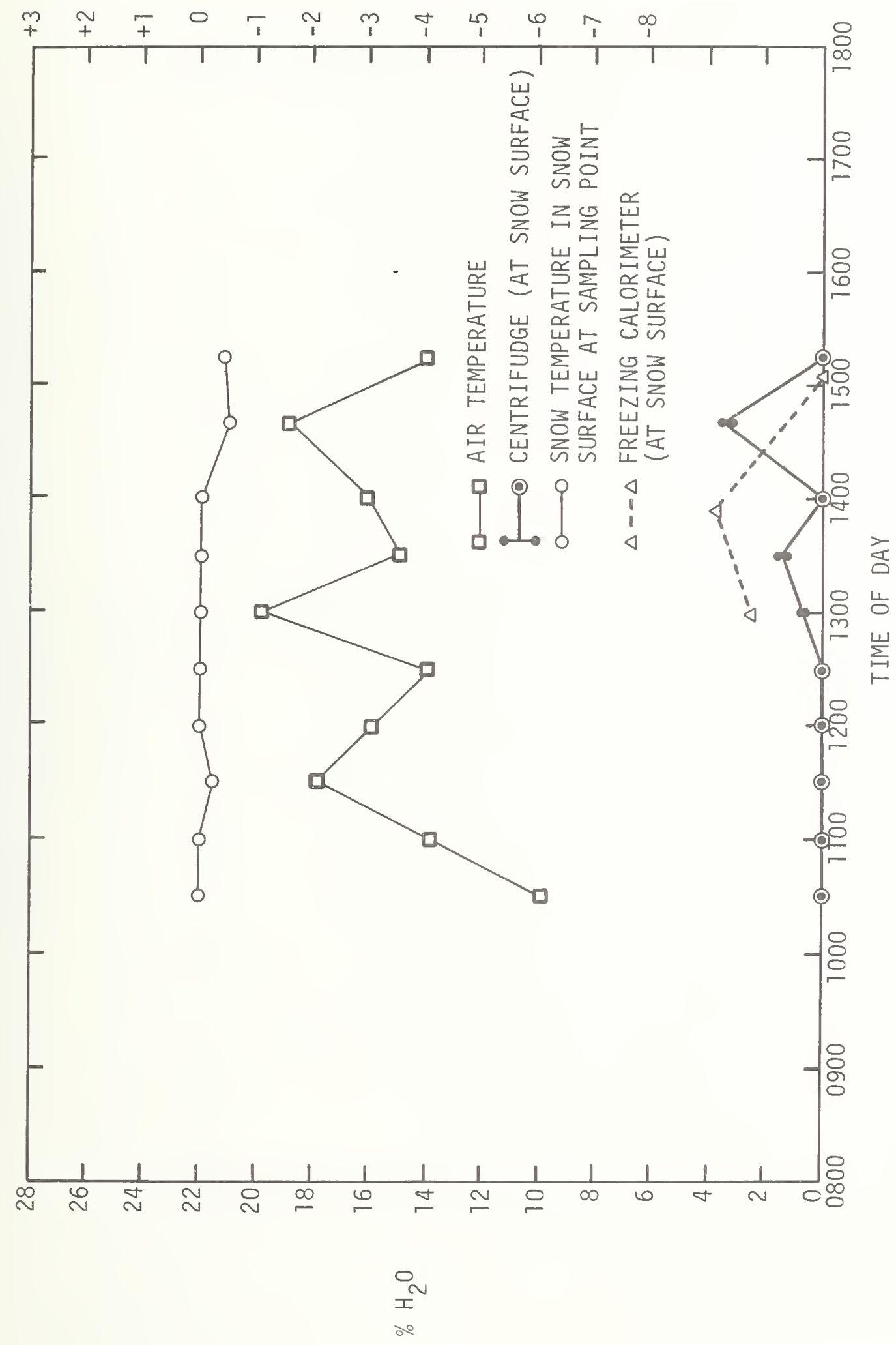

D 
ว。 $\exists y \cap \perp \forall y \exists d W \exists \perp$

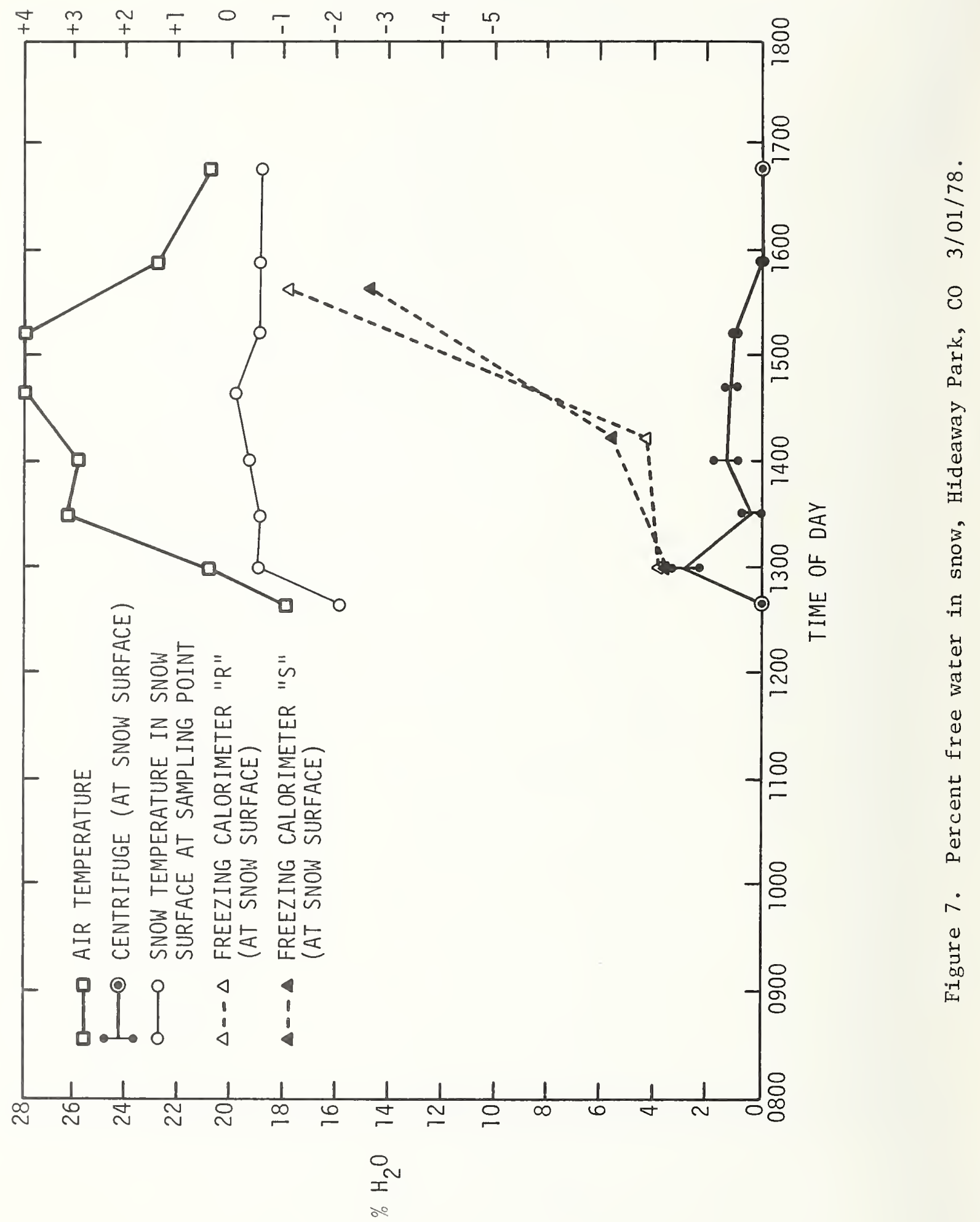


ว。 $\exists y \cap \perp \forall y \exists d W \exists \perp$

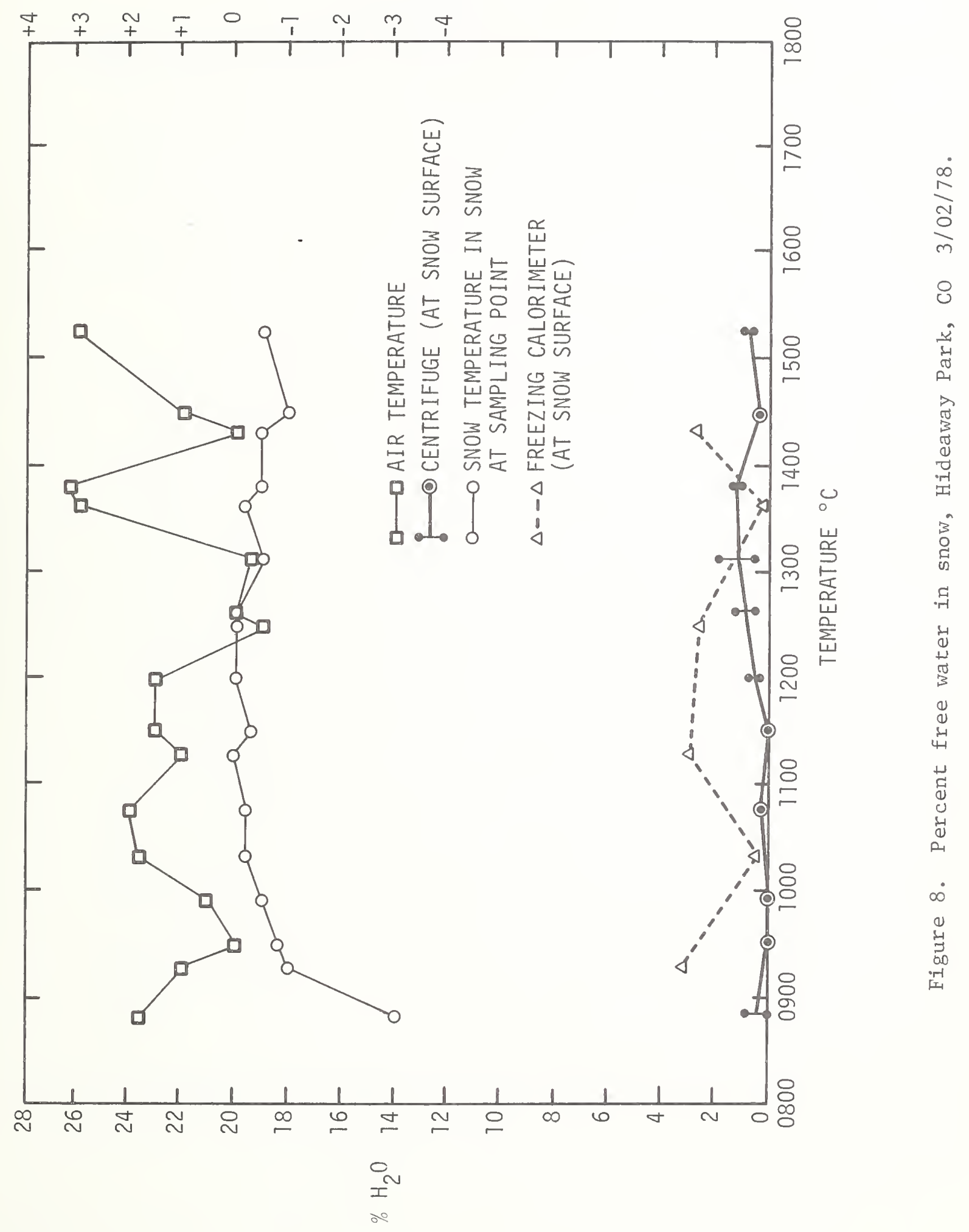


ว。 $\exists y \cap \perp \forall y \exists d W \exists \perp$

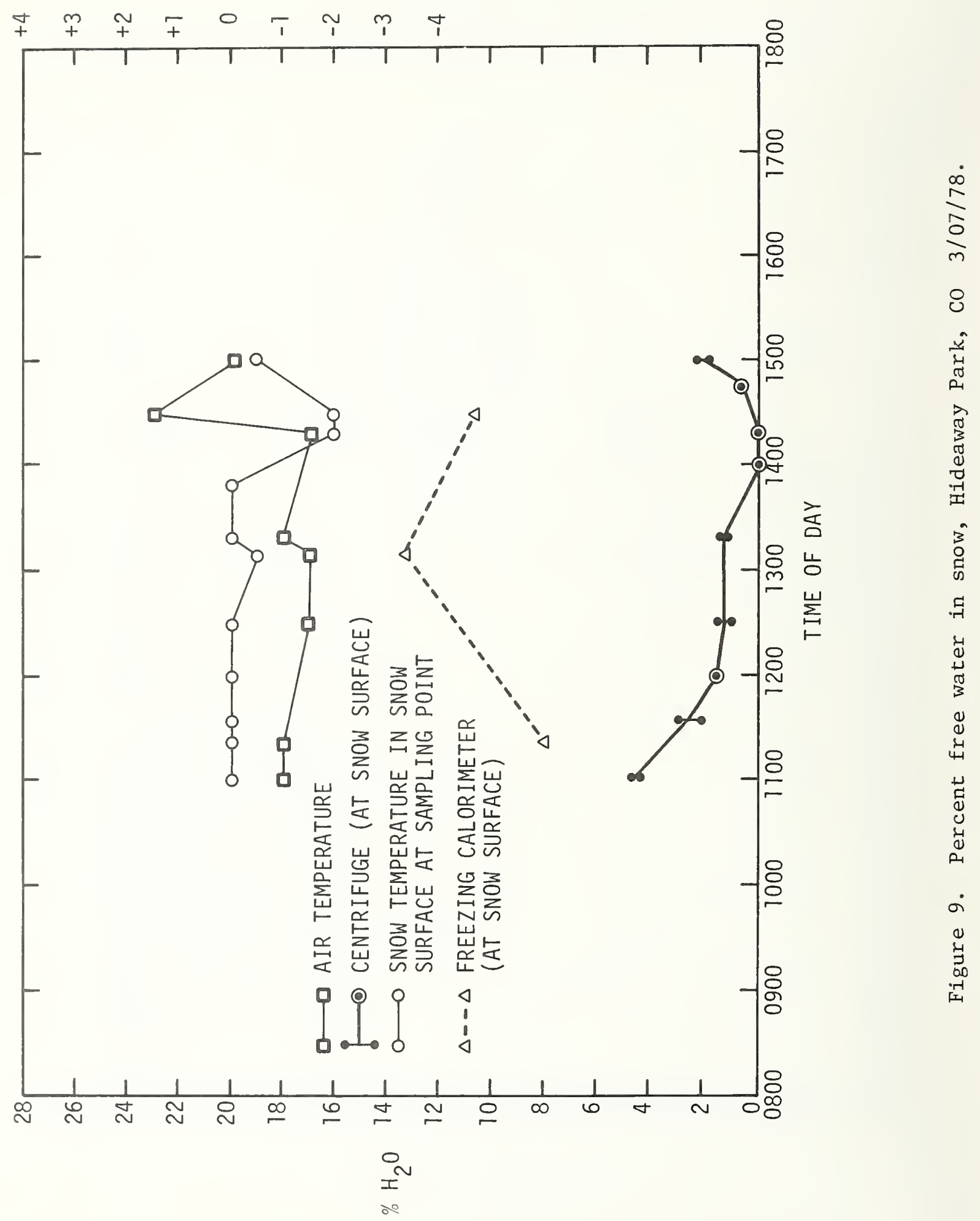


ว。 $\exists y \cap \perp \forall y \exists d W \exists \perp$

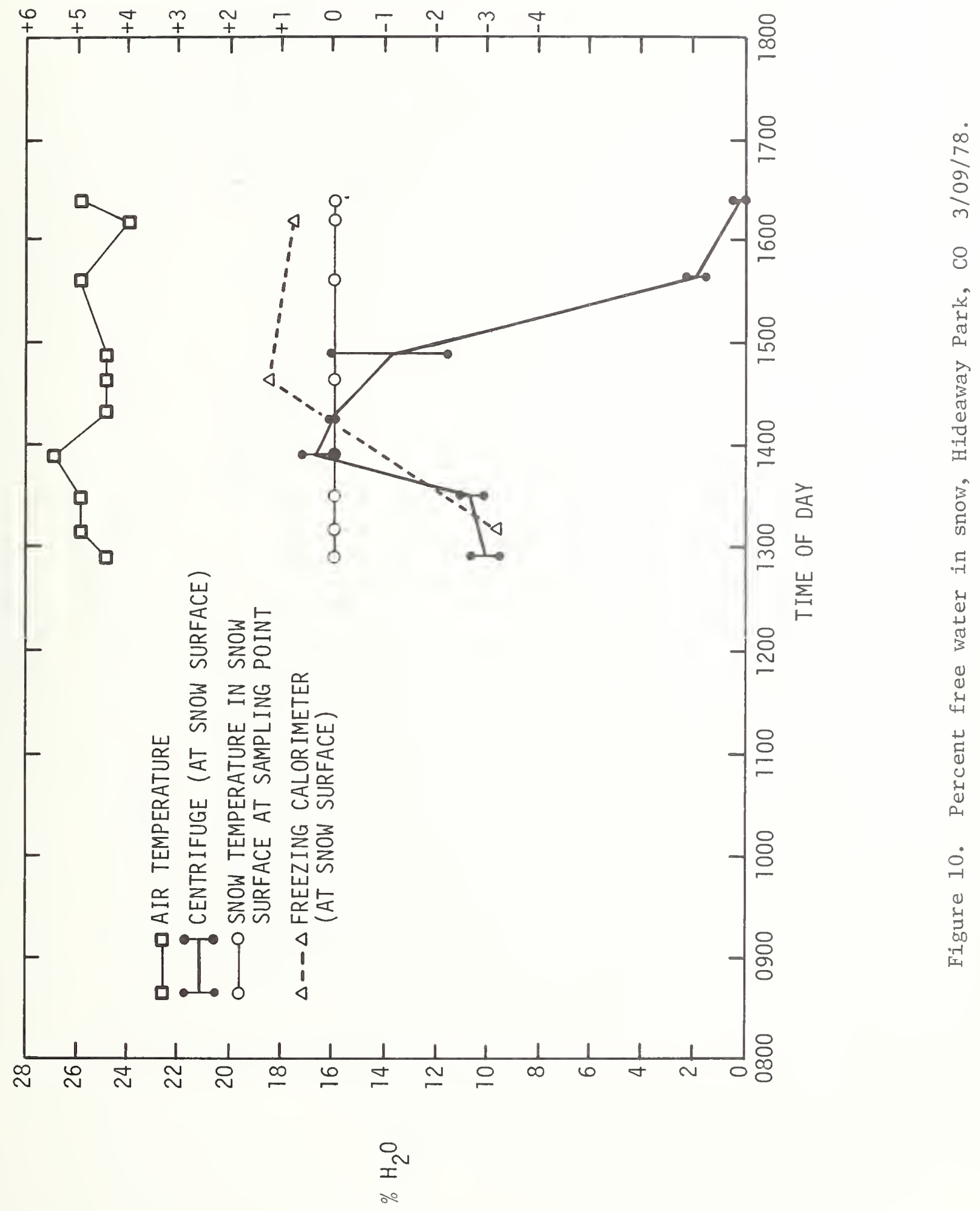


ว。 $\exists y \cap \perp \forall y \exists d W \exists \perp$

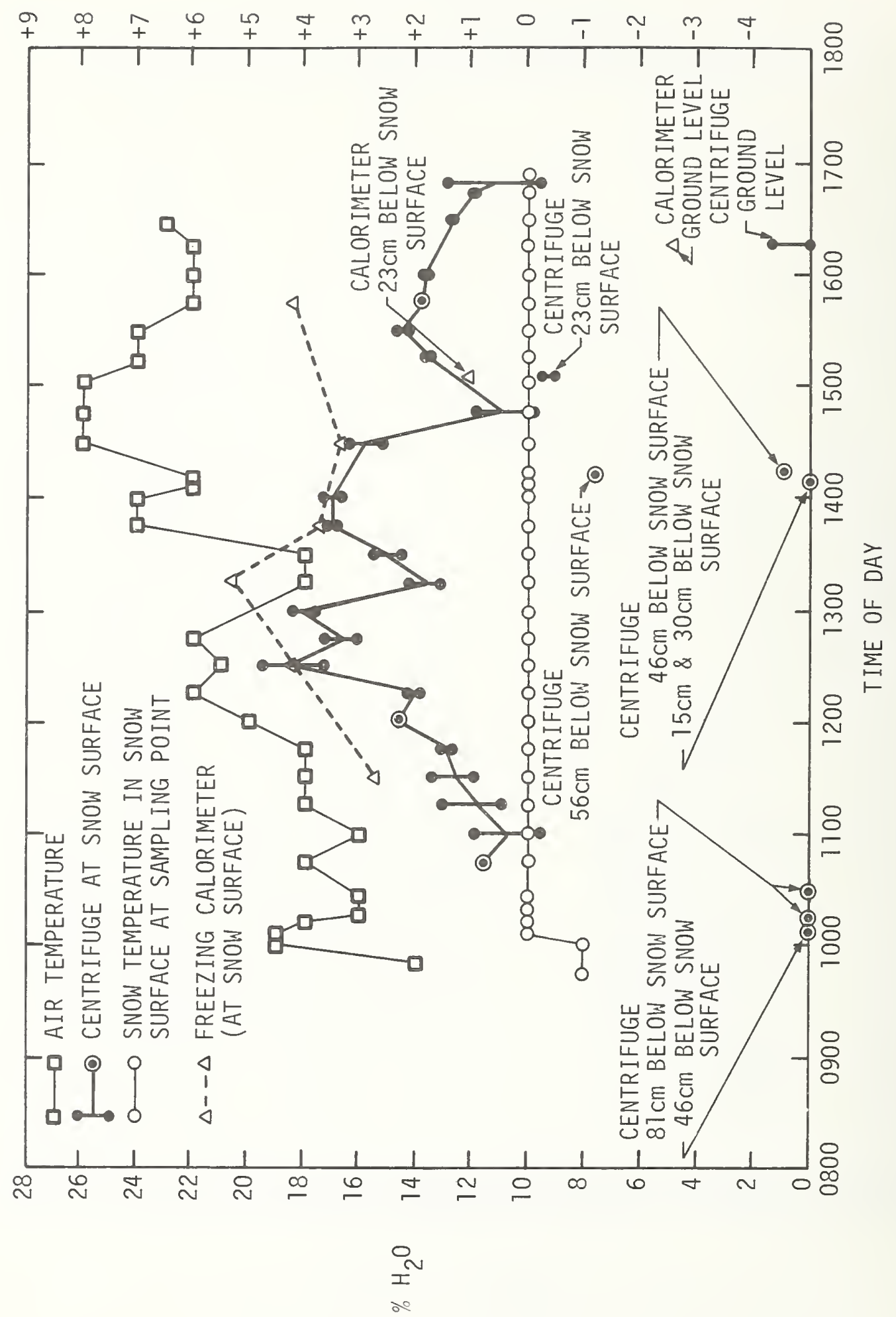

D 
$J_{0} \exists y n \perp \forall y \exists d W \exists \perp$

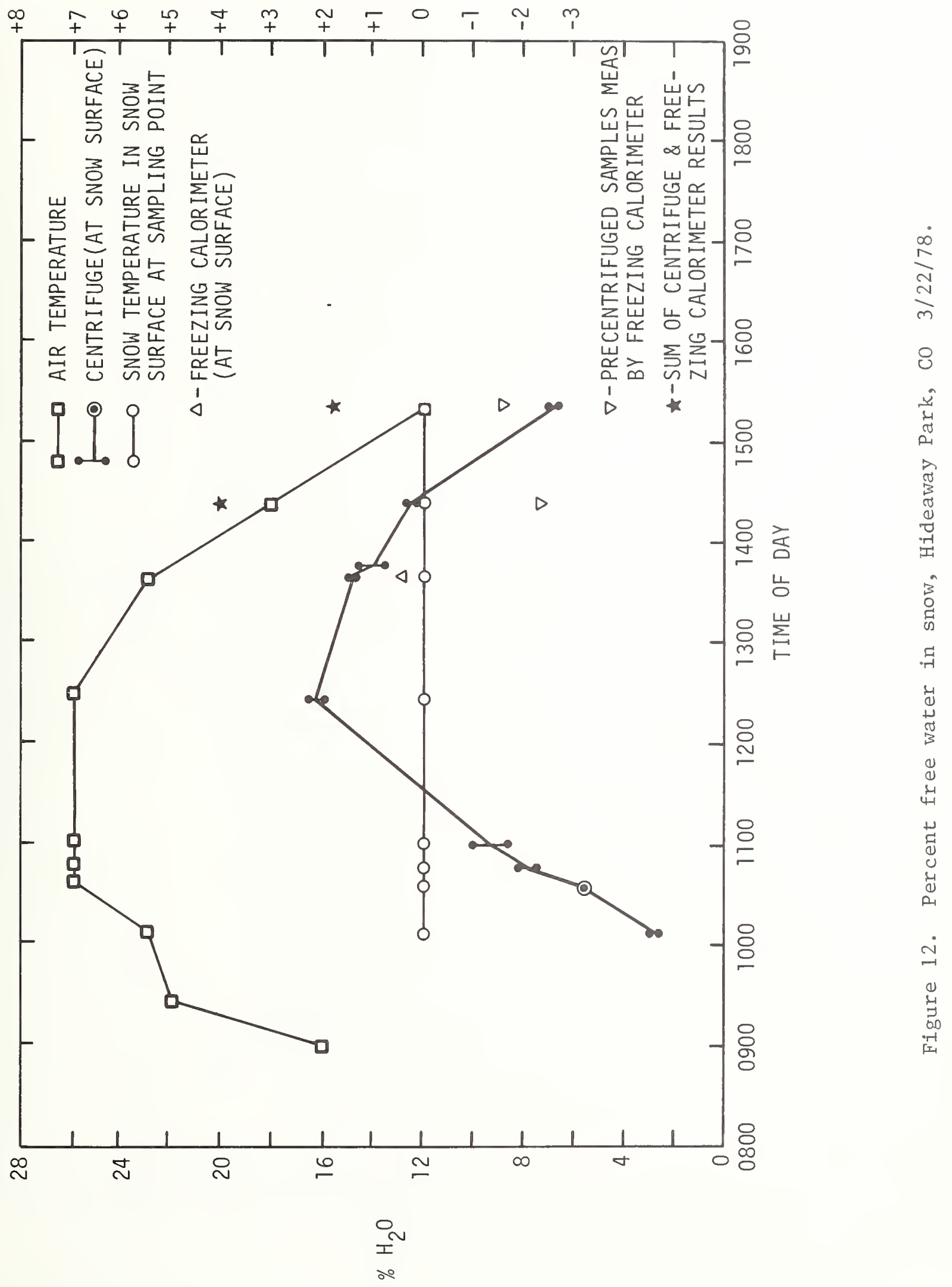


ว。 $\exists y \cap \perp \forall y \exists d W \exists \perp$

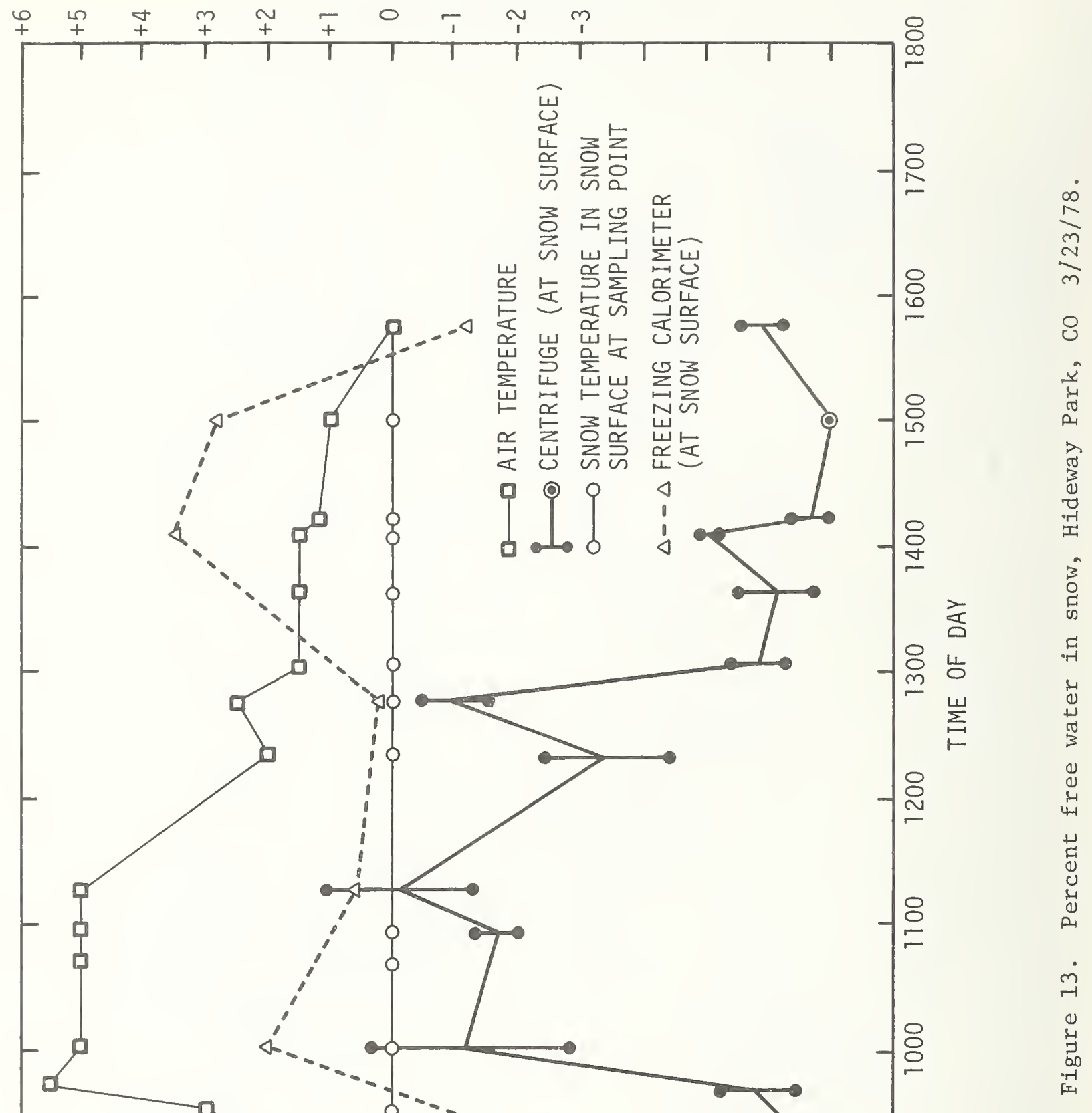


ว。 $\exists y \cap \perp \forall y \exists d W \exists \perp$

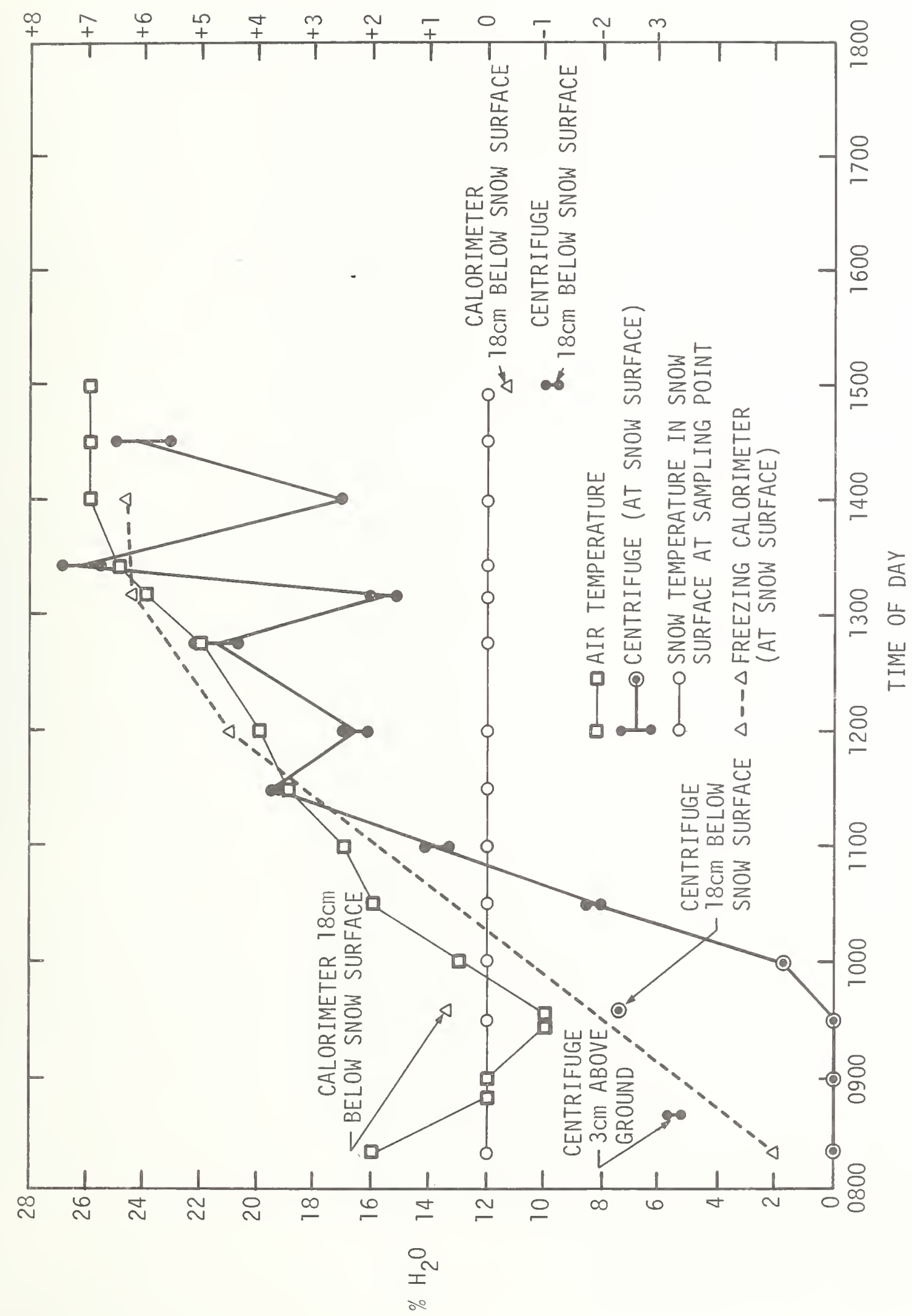


Three sand samples were prepared, each having a total volume of approximately $20 \mathrm{ml}$. The samples were screened to have only particles in a specific size range. The sizes are shown in Table 2. A centrifuge tube like those shown in figure 2 was used except that the bottom tip of the tube was cut off to allow the centrifuged free water to escape. The sand samples were dried and weighed. After weighing, they were thoroughly moistened by pouring water through the open ended tube. Then, after centrifuging, the sample was reweighed to give the amount of water still remaining in the sand. These results are also shown in Table 2 as percent of water retained by weight. Taking the density of an average snow sample to be $0.25 \mathrm{~g} / \mathrm{cc}$ and multiplying the percent of water weight retained by the sand by the ratio of the density of sand to that of snow, we arrive at percentage of water by weight retained by snow. These are 26 percent, 10.6 percent, and 5.6 percent for samples 1 , 2 , and 3, respectively. These values appear to be typical of the differences observed between calorimeter and centrifuge results. It shows that for large particle sizes, the correction for retained water by centrifuge is much smaller than in instances where the particle size is small. This suggests that centrifuge results can be corrected to agree with freezing calorimeter data simply by adding an empirical correction based on snow density and particle size and that sand can be used as the medium for determining these empirical corrections. 
Table 2 Water Retained by Sand after Centrifuging

Percent Equivalent

Retained $\mathrm{H}_{2} \mathrm{O}$

Sample Particle Size (m) Retained $\mathrm{H}_{2} \mathrm{O}$ Sand Dry Density for Snow
No.
Min.
$\operatorname{Max}$
(\% by weight)
$\mathrm{g} / \mathrm{cc}$
of Density $0.3 \mathrm{~g} / \mathrm{cc}$

$\begin{array}{rrrrrr}1 & 0 & 1 & 4.8 & 1.38 & 22 \\ 2 & 1 & 5 & 1.9 & 1.40 & 8.9 \\ 3 & 5 & 10 & 1.0 & 1.46 & 4.9\end{array}$

This approach appears to have some potential except in instances where the centrifuge method indicates no free water. Assuming similar behavior between snow and sand, then there is the possibility that appreciable, undetected free water may be present especially where grain structure is very fine or the snow crystals have large surface areas. In these instances, the centrifuge results cannot be corrected to agree with the calorimeter results.

The foregoing discussion is not to be interpreted as a condemnation of the centrifuge method because it is certainly possible that the free water presence indicated thereby is the most relevant to a particular situation, say avalanche conditions for example. Also, calorimeter measurements may provide the best information for yet a different aspect 
of snow studies. It does appear obvious, however, that whatever the ultimate purpose for free water determinations, little agreement between the two methods can be expected.

\section{CONCLUSIONS}

1. From the measurement data reported, it is concluded that the centrifuge and freezing calorimeter method results do not measure the same phenomena and that water may be present in snowpack in a form which is detectable by the freezing calorimeter method but not by the centrifuge method.

2. Because of the many instances where the two centrifuge results of a single operation varied by significant amounts, it is concluded that the amount of free water present may vary by several percent over distances of $50 \mathrm{~cm}$ or less.

3. Because of the disagreement in free water content as determined by these two methods and other methods as well, it is apparent that work is needed to determine which method gives results which correlate best with microwave phenomena. For data taken by various experimenters at different times and locations to have a common basis for comparison, it is evident that a uniform method should be adopted. 


\section{APPENDIX I}

The following two pages show the type of data sheet used in carrying out the freezing calorimeter experiments and a typical time vs. temperature plot of the calorimeter temperature before and after adding the snow sample. From the time vs. temperature plot, it can be seen how the before and after sample addition temperature plots are extrapolated to provide the temperature increment due to the snow sample. This information, together with the other information shown on the data sheet, is used to compute the percent of free water in the snow sample. 
Time Temp ${ }^{\circ} \mathrm{C}$

$0-46.0$

$1-38.4$

$1.5=37.9$

2

$2.5-37.0$

$3-36.6$

$3.5-36.3$

$4 .-35.9$

$4.5=35.6$

$5-35.3$

$5.5-35.0$

$6-34.7$

$6.5-34.4$

$7-34.2$

$7.5-33.9$

$8-33.6$

8.5

9

9.5

10

$10.5=13.0$

$11-12.6$

$11.5-12.4$

$12-12.2$

$12.5=12.1$

$13-12.0$

$13.5=11.9$

$14-11.8$

$14.5=11.7$ $15-11.6$ $15.5-1 / .5$ $16-11.4$ $\underline{16.5}=1 / .3$ $17-11.2$ $17.5=11 . \mathrm{L}$ $18-11.0$
Station Hideaway Perk, CO. observer R.N.Clones

Date $3 / 9 / 78$ Hour 1610

Location and description of sampling point sampletaken from

upper surface of snow

Data

Sample thermos No. 102 Air Temperature

Height of sample from ground surface $\mathrm{cm}$.

(1) Tare weight of calorimeter gr.

(2) Weight of calorimeter and silicone fluid gr.

(3) Weight of calorimeter + silicone fluid + snow $/ 74435 \mathrm{gr}$.

(4) Calorimeter constant (E) $89.0 \mathrm{gr}$.

(5) $t_{1}=-32.85 t_{2}=-12.75 \Delta \mathrm{T}=20.1^{\circ} \mathrm{C} \quad t_{\mathrm{s}}=$ $0^{\circ} \mathrm{C}$

(6) $(2)-(1)=366.15$

$$
\text { (3) }-(2)=196.25
$$

Heat Balance

WiCi $\left(t_{2}-t_{1}\right)-t_{2} C_{S} S=L F$

where

$W i=(2)-(1)+E, g r$.

$\mathrm{C}_{\mathrm{S}}=$ specific heat of ice

$\mathrm{Ci}=$ specific heat of silicone

$t_{1}=$ initial temp. ${ }^{\circ} \mathrm{C}$

$\mathrm{S}=(3)-(2), \mathrm{gr}$.

$t_{2}=$ final temp. ${ }^{\circ} \mathrm{C}$

$\mathrm{L}=$ latent heat of melting

$t_{\mathrm{S}}=$ snow temp ${ }^{\circ} \mathrm{C}$

$\mathrm{F}$ = weight of free water, gr.

$t_{3}=t_{2}-t_{s}$

Snow Quality

$\mathrm{Q}_{\mathrm{f}}=1-\left[\mathrm{Wi} \mathrm{Ci}\left(\mathrm{t}_{2}-\mathrm{t}_{1}\right) / \mathrm{LS}\right]-\left[\mathrm{C}_{\mathrm{s}} \mathrm{t}_{3} / \mathrm{L}\right]$

$Q_{f}=1-[455.15 \times .4350 \times 20.1 / 79.71 \times 196.25][-492 \times-12.75 / 79.71]$

$q_{f}=1-0.254+0.079$

$Q_{f}=0.825$ or $17.5 \% \mathrm{H}_{2} \mathrm{O}$ 


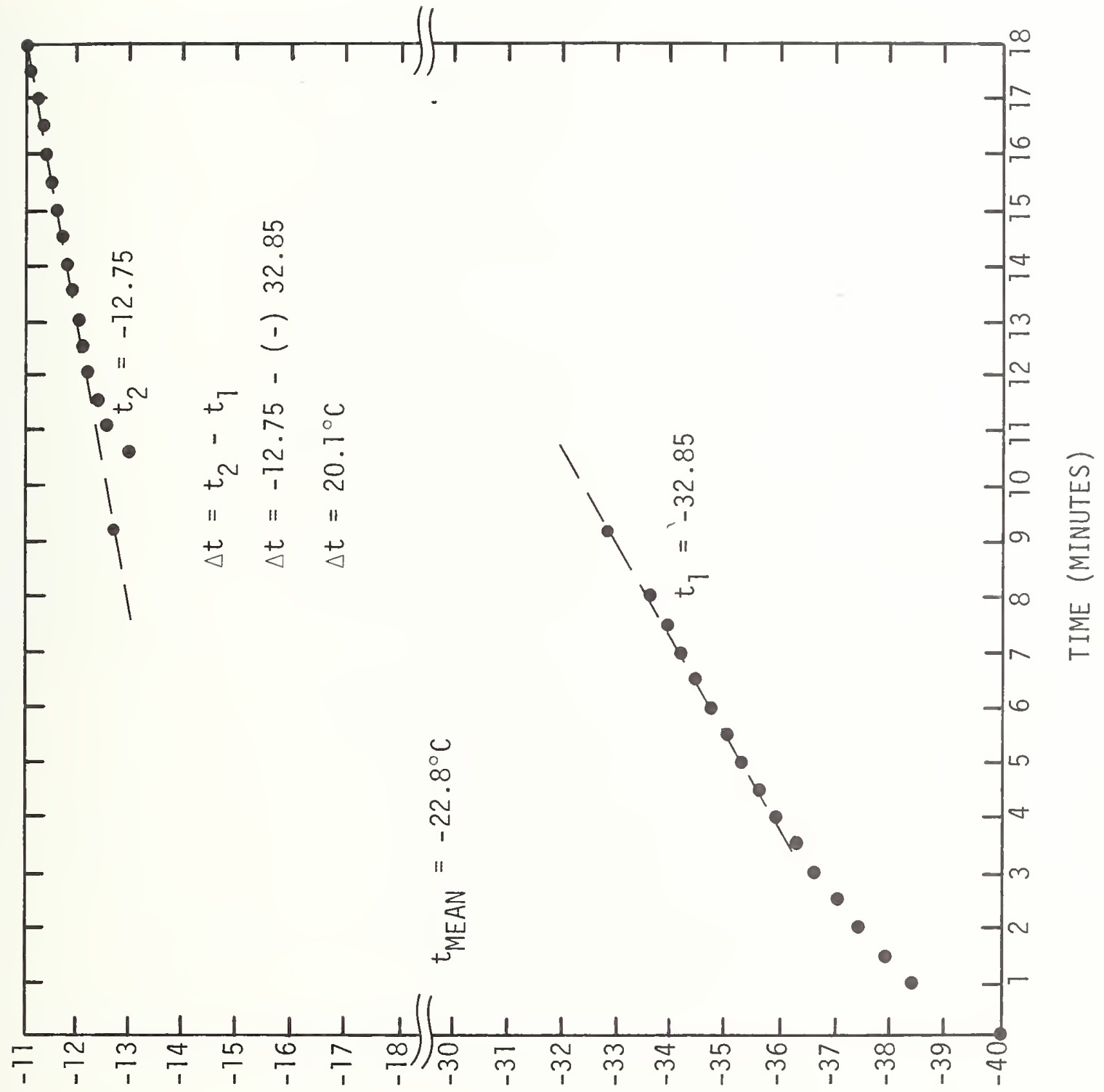

J。 $\exists y \cap \perp \forall y \exists d W \exists \perp$ 

Beginning with the equation for free water content

$$
Q_{f}=-\left[W_{i} C_{i} \Delta t / L S\right]-\left[C_{S} t_{3} / L\right]
$$

where $\Delta t=t_{2}-t_{1}$, the extrapolated calorimeter temperatures before and after adding the snow sample, and $t_{3}=t_{2}-t_{s}$, an error analysis of the procedure can be carried out mathematically. This is done by taking the partial derivative of $Q_{f}$ with respect to each variable in equation (1). Since there are seven variables, namely $L, S, W_{i}, C_{i}, \Delta t, C_{S}$, and $t_{3}$, seven expressions result which can be evaluated numerically to give an estimated error contribution from each one. Then, because these give both positive and negative errors, which may or may not be compensating in a particular situation, they are combined as the square root of the sum of the squares to give an uncertainty estimate. The seven error expressions are the following:

$$
\begin{gathered}
\frac{\partial Q_{f}}{\partial L}=\frac{L S^{2}-\left[L S-W_{i} C_{i} \Delta t-S C_{S} t_{3}\right] S}{L^{2} S^{2}} d L \\
\frac{\partial Q_{f}}{\partial S}=\frac{L S\left[L-C_{S} t_{3}\right]-\left[L S-W_{i} C_{i} \Delta t-S C_{S} t_{3}\right] L}{L^{2} S^{2}} d S
\end{gathered}
$$




$$
\frac{\partial Q_{f}}{\partial W_{i}}=\frac{L S\left[-C_{i} \Delta t\right]}{L^{2} S^{2}} d W_{i}
$$

$$
\frac{\partial Q_{f}}{\partial C_{i}}=\frac{L S\left[-W_{i} \Delta t\right]}{L^{2} S^{2}} d_{i}
$$

$$
\frac{\partial Q_{f}}{\partial \Delta t}=\frac{L S\left[-W_{i} C_{i}\right]}{L^{2} S^{2}} d(\Delta t)
$$

$$
\frac{\partial Q_{f}}{\partial C_{S}}=\frac{L S\left[-S t_{3}\right]}{L^{2} S^{2}} d C_{S}
$$

$$
\frac{\partial Q_{f}}{\partial t_{3}}=\frac{L S\left[-C_{S} S\right]}{L^{2} S^{2}} d t_{3}
$$

The total differential, $\mathrm{dQ}_{\mathrm{f}}$, which is the uncertainty is:

$\mathrm{dQ}_{\mathrm{f}}=\frac{\partial \mathrm{Q}_{\mathrm{f}}}{\partial \mathrm{L}} \mathrm{dL}+\frac{\partial \mathrm{Q}_{\mathrm{f}}}{\partial \mathrm{S}} \mathrm{dS}+\frac{\partial \mathrm{Q}_{\mathrm{f}}}{\partial \mathrm{W}_{i}} \mathrm{dW}+\frac{\partial \mathrm{Q}_{\mathrm{f}}}{\partial \mathrm{C}_{i}} \mathrm{dC}_{i}+\frac{\partial \mathrm{Q}_{\mathrm{f}}}{\partial \Delta t} \mathrm{~d} \Delta t+\frac{\partial \mathrm{Q}_{\mathrm{f}}}{\partial \mathrm{C}_{\mathrm{S}}} \mathrm{dC}_{\mathrm{S}}+\frac{\partial \mathrm{Q}_{\mathrm{f}}}{\partial \mathrm{t}_{3}} \mathrm{dt} \mathrm{t}_{3}$

Taking the example of Appendix I and using the following set of values for the parameters and the corresponding uncertainty estimates: 


$$
\begin{array}{rlrl}
\mathrm{L} & =79.7 & \mathrm{dL} & =0.3 \\
\mathrm{~S} & =196.25 & \mathrm{dS} & =4 \\
\mathrm{~W}_{\mathrm{i}} & =255.15 & \mathrm{dW}_{\mathrm{i}} & =12 \% \\
\mathrm{C}_{\mathrm{i}} & =0.435 & \mathrm{dC}_{\mathrm{i}} & =0.01 \\
\Delta \mathrm{t} & =20.1 & \mathrm{~d}(\Delta \mathrm{t}) & =0.01 \\
\mathrm{C}_{\mathrm{S}} & =0.492 & \mathrm{dC}_{\mathrm{S}} & =0.01 \\
\mathrm{t}_{3} & =12.75 & \mathrm{dt}_{3}=0.2
\end{array}
$$

an uncertainty of \pm 1.2 percent is obtained for the free water content.

In two other examples that were similarly analyzed, values of 25.2 percent $( \pm 2.4$ percent $)$ and 4.1 percent $( \pm 1.0$ percent $)$ were obtained. Thus, the estimated uncertainty of 1 to 2 percent for the method appears reasonable.

The quantity $\mathrm{dW}_{i}=12$ includes an allowance of 8 grams for the uncertainty for the thermal mass of the calorimeter. This was the standard deviation among twelve experiments which were performed in calibrating the calorimeter. 


\section{ACKNOWLEDGMENT}

The work described was done under the sponsorship of the National Aeronautics and Space Administration (NASA) Goddard Space Flight Center of Greenbelt, Maryland, U.S.A. Mr. James C. Shiue was the project coordinator. Much valuable assistance in the use of the freezing calorimeter method was received from Messers Steve Howell and Dave Frick of Resource Consultants, Inc., of Fort Collins, Colorado. The very able assistance and support of these people is very much appreciated. Also, Doyle Ellerbruch and Ron Whitman of NBS supplied much needed help with the measurement procedures. To all of you, my sincere thanks. 
[1] Chang, T. C., and Gloersen, Microwave Emission from Dry and Wet Snow, Operational Applications of Satellite Snowcover Observations, NASA SP-391, Washington, D.C., pp. 399-407, 1975.

[2] Hall, D. K., A. Chang, J. L. Foster, A. Rango, T. Schmugge, Passive Microwave Studies of Snowpack Properties, NASA Technical Memorandum 78089, Goddard Space Flight Center, Greenbelt, MD, April 1978 (Presented at the Western Snow Conference, 1974), pp. 60-71.

[3] Langham, E. J., Problems of Measuring Meltwater in the Snowpack, Proc. Eastern Snow Conference, 1974, pp. 60-71.

[4] Bergman, J. A., A Method for the Determination of Liquid Phase Water in a Snowpack Using Toluene Freezing Calorimetry, Masters Thesis, Dept. of Forestry, Univ. of Nevada, Reno, May 1978.

[5] LaChapelle, E. R., The Centrifugal Separation of Free Water from Melting Snow, J. of Glaciology 2, pp. 769-771, 1956.

[6] Langham, E. J., Measurement of Liquid Water Content of Snow by Repeated Centrifugal Extraction, Tech. Report Glaciology Division, Inland Waters Directorate, Water Resources Branch, Dept. of Fisheries and Environment, Ottawa, Canada, 1978.

[7] Carroll, T., Estimation and Prediction of the Liquid Water Distribution in a High Altitude Spring Snowpack, Avalanche Workshop sponsored by NRC, British Columbia Highway Dept., Parks Canada, and the University of Calgary in Banff, Alberta, Nov. 1-4, 1976.

[8] Radok, U., S. K. Stephens, and U. R. Sutherland, on the Calorimetric Determination of Snow Quality, U.G.G.I. Assembly, Commission of Snow and Ice, Helsinki, 1960, I.A.S.H. No. 54, pp. 132-135.

[9] Leaf, Charles F., Free Water Content of Snowpack in Subalpine Areas, Proceedings of the 34th Annual Western Snow Conference, Seattle, Washington, April 19-21, 1966. 
NBS-114A (REV, 9-78)

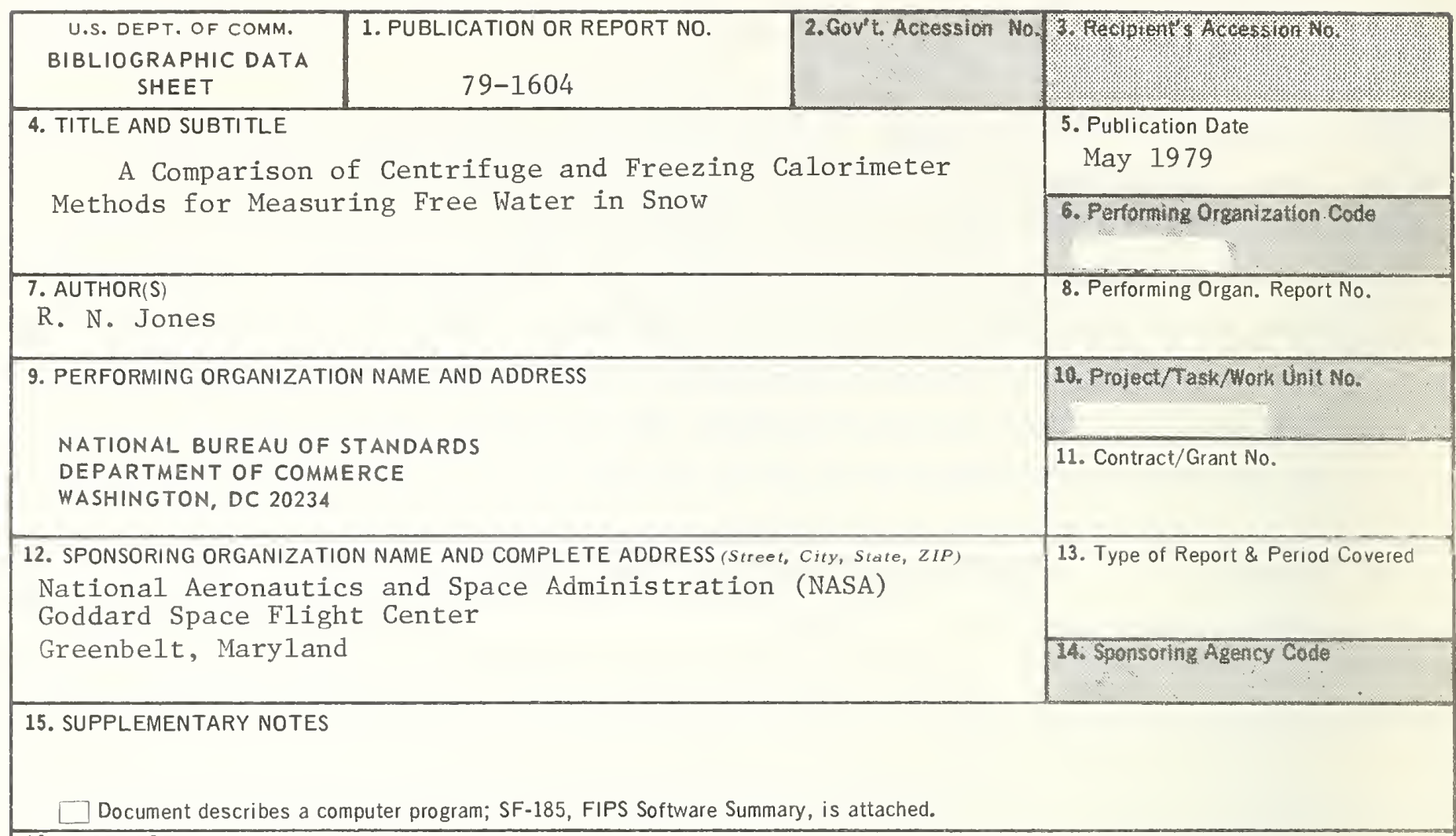

16. ABSTRACT (A 200-word or less factual summary of most significant information. If document includes a significant bibliography or literature survey, mention it here.)

In using microwave measurements in hydrological scudies of snowpack or avalanche prediction, the presence of free water in the snow has a strong influence on observed data because it affects the dielectric characteristics. Although several methods are in use for determining the percent of free water in snow, there is very little information in the literature as to how well the various methods agree. This paper reports on a comparison of two popular methods; namely, the centrifuge and the freezing calorimeter. Results from measurements over a two-month period in the Colorado mountains in the winter of 1978 indicate serious disagreement between these two methods. Some reasons for the disagreement are presented and verified. This raises some important questions pertaining not only to what the two methods actually measure, but also which methods may be appropriate for particular applications.

17. KEY WORDS (six to twelve entries; alphabetical order; capitalize only the first letter of the first key word unless a proper name; separated by semicolons)

Centrifuge; comparison of measurement methods;

free water; freezing calorimeter; hydrology forecasting; microwave remote sensing; snow.

\begin{tabular}{|c|c|c|}
\hline $\begin{array}{l}\text { 18. AVAILABILITY Unlimited } \\
\square \text { For Official Distribution. Do Not Release to NTIS }\end{array}$ & $\begin{array}{l}\text { 19. SECURITY CLASS } \\
\text { (THIS REPORT) } \\
\text { UNCLASSIFIED }\end{array}$ & $\begin{array}{l}\text { 21. NO. OF } \\
\text { PRINTED PAGES } \\
44\end{array}$ \\
\hline $\begin{array}{l}\text { Order From Sup. of Doc., U.S. Government Printing Office, Wasinington, DC } \\
20402 \text {, SD Stock No. SN003-003- } \\
\text { X Order From National Technical Information Service (NTIS), Springfield, } \\
\text { VA. } 22161\end{array}$ & $\begin{array}{l}\text { 20. SECURITY CLASS } \\
\text { (THIS PAGE) } \\
\text { UNCLASSIFIED }\end{array}$ & $\begin{array}{l}\text { 22. Price } \\
\$ 4.00\end{array}$ \\
\hline
\end{tabular}




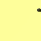


